\title{
Malaria and anemia among pregnant women living in communities along the coast of Lagos Lagoon, South-west Nigeria
}

\begin{abstract}
Background: Malaria parasitemia during pregnancy is a most important public health problem to governments and to individuals in malaria endemic regions of the world. Moderate or severe anemia during pregnancy may be associated with heavy parasitic infestation. However, malaria may not be the only cause of anemia in pregnant women in developing countries.
\end{abstract}

Objective: To determine the prevalence of malaria and anemia in different trimester, gravida and age group

Study design: A cross-sectional study that recruited 113 pregnant women who were screened for the malaria parasites and anemia.

Setting: The study was conducted in the antenatal clinic of two general hospitals in Ikorodu Local Government Area (LGA) in Lagos, Southwest Nigeria.

Participants: The pregnant women recruited for this study were living in communities on the coasts of the Lagos Lagoon.

Measurements: Socio-demographic profile, obstetrics and gynecologic history and other relevant data of the pregnant women were collected using a semi-structured questionnaire instrument in an interview. Blood samples were analyzed for Packed Cell Volume (PCV) level and malaria parasites

Results: Malaria prevalence was $19.5 \%$ and the prevalence of anemia was $81.4 \%$. The highest prevalence of malaria $(27.5 \%)$ occurred in the $3 \mathrm{rd}$ trimester and among primigravida. The highest prevalence of anemia was in the 2 nd trimester and among the multigravida. Those with severe anemia were approximately five times more likely to have malaria parasitemia $\left(\chi^{2}=8.16, \mathrm{P}\right.$-value $=0.004, \mathrm{OR}=4.84,95 \% \mathrm{CI}: 1.53$, $15.35)$ compared to all other pregnant women. Women in the third trimester were 1.25 as likely to develop severe anemia than those in first or second trimester $\left(\chi^{2}=0.18\right.$, $\mathrm{P}$-value $=0.69, \mathrm{OR}=1.25,95 \% \mathrm{CI}=0.41,3.82)$. Secundigravida were 1.60 times more likely to develop moderate anemia $\left(\chi^{2}=1.20, \mathrm{P}\right.$-value $=0.27, \mathrm{OR}=1.60,95 \% \mathrm{CI}=0.69$, $3.76)$ and multipara were 1.35 times more likely to develop mild anemia $\left(\chi^{2}=024\right.$, $\mathrm{P}$-value $=0.62, \mathrm{OR}=1.35,95 \% \mathrm{CI}=0.41,4.47)$. Regardless of whether the pregnant woman was parasitized or not, the mean PCV of those who consumed herbal tea $(28.2 \pm 5.2)$ was significantly lower $(\mathrm{t}=-2.24$, P-value $=0.01)$ than those who did not consume herbal tea $(30.8 \pm 6.5)$ in pregnancy.

Conclusion: The prevalence of anemia in pregnancy was very high while the prevalence of malaria was very low. Anemia was commoner in the 2 nd trimester and among multigravida while malaria was more prevalent in the 3 rd trimester and among primigravida. Consumption of herbal tea was associated with low Packed Cell Volume.

Keywords: pregnancy, malaria, anemia, maternal age, trimester, gravidity, Southwest Nigeria
Volume 4 Issue 6 - 2018

\author{
Adeola Olukosi,' Bamgboye M Afolabi,2 \\ 'Nigerian Institute of Medical Research, Nigeria \\ ${ }^{2}$ Health, Environment and Development Foundation, Nigeria
}

Correspondence: Bamgboye M Afolabi, Health, Environment and Development Foundation, 18 Ogunfunmi Street, off Akobi Crescent, Surulere, Lagos, Nigeria, Email bmafulabi@gmail.com

Received: October 16,2018 | Published: November 08, 2018

\section{Introduction}

It is estimated that, annually, about 30 million pregnant African women are exposed to the risk of malaria infection ${ }^{1}$ and 56 million suffer anemia. In regions of intense transmission, infection with Plasmodium falciparum is usually asymptomatic and therefore undetected and untreated although the malaria parasites are incubated in the placenta. ${ }^{2}$ Various studies have reported main adverse effects of malaria in pregnancy such as maternal anemia and low birth weight babies. ${ }^{3-5}$ Individuals in endemic areas build up immunity against malaria by acquiring specific antibodies capable of hindering parasite sequestration. ${ }^{6}$ However, pregnant women are susceptible to infection, despite previously acquired immunity probably because of her lowered immune response and reduced ability to effectively clear malaria parasites from her system. ${ }^{7,8}$ Furthermore, probably because of its high nutrient and oxygen content, malaria parasites sequester in the placenta, more than in the peripheral blood, though Pereira et al. ${ }^{9}$ stated that the specific adherence of malaria parasites to placenta tissues is mediated by a certain protein, the VAR2CSA protein, which binds to placental chondroitin sulfate (CS) on chondroitin sulfate proteoglycans (CSPGs) in the placental syncytium. ${ }^{9}$ Clinical complications such as anemia, pulmonary edema, hypoglycemia, cerebral malaria, puerperal sepsis, miscarriage, premature delivery, low birth weight, congenital infection, and/or perinatal death are possible outcomes of malaria 
infection during pregnancy. ${ }^{10-16}$ It is pertinent to note however that anemia is especially problematic because hemoglobin level falls due to greater expansion of plasma volume relative to increase in red RBC volume, especially so in the second trimester of cases. It has been shown that anemia increase when there is elevated number of malaria cases ${ }^{17}$ and the incidence of anemia during pregnancy is aggravated in malaria high-transmission settings. These adverse effects of $P$. falciparum infection in pregnancy are most pronounced for women in their first pregnancy. ${ }^{18,19}$ In addition to malaria parasite-induced hemolysis during infection, iron deficiency heightened by nutritional deficiencies can result in iron-deficiency anemia; folate-deficiency anemia or Vitamin B12-deficiency anemia and worm infestation worsen the anemia situation in the general populace and in pregnancy, foretells poor maternal outcomes. ${ }^{20-22}$ Interventions are therefore targeted at this group of people to abate the problems and surveillance of the affected population becomes necessary to monitor the impact periodically. The objective of this study was to examine the pattern of anemia among pregnant women in Lagos Nigeria and describe the proportion of the anemia due associated with malaria parasitemia. Intervention can therefore be better targeted. Furthermore, proportion of anemic pregnant women due from malaria infection can be deduced separate from anemia due to other causes.

\section{Materials and methods}

This cross-sectional study, implemented from January to April of 2009, at the antenatal clinics of Ijede General Hospital and Ikorodu General Hospital in Ikorodu Local Government Area (LGA), two government operated facilities in Lagos, Southwest Nigeria, has been reported elsewhere. ${ }^{23}$ Ikorodu General Hospital is located in the urban center of the LGA whereas Ijede General Hospital is located in its rural parts, approximately $8 \mathrm{~km}$ further eastwards. Both Health facilities are located within communities adjacent to the northern fringe of the Lagos lagoon. Ikorodu, a semi-urban town, is the headquarters of Ikorodu LGA which lies between latitude $6037^{\prime} \mathrm{N}-6045^{\prime} \mathrm{N}$ and longitude 303'East-305'East. Population migration from metropolitan Lagos and other parts of Nigeria has increased the population of this LGA from about 400,000 in 2000 to over 700,000 in 2009, though Ijede residents were still mainly a homogenous population of approximately $10-15,000$, made up of farmers, fishermen and petty traders. There were three primary schools and one secondary school in Ijede. Due to its proximity to Lagos, the community still has good access road, pipe borne water and relatively stable electric supply. By contrast, Ikorodu, because of its size and semi-urban features, has a network of tarred roads, more public and private health and educational facilities and is supplies with large markets where entrepreneurs ply their trade. Some of the residents at Ikorodu and Ijede work in offices in metropolitan Lagos, commuting either by road or by water transportation over the lagoon of Lagos.

\section{Sample size calculation for each health facility}

Sample size was calculated assuming a prevalence of $20 \%$ for malaria in pregnancy, for an error rate of $10 \%$ and a confidence interval of $95 \%$, the sample size needed is

$$
\frac{Z^{2} p q}{d^{2}}=\frac{1.96^{2} \times 0.2 \times 0.8}{0.1^{2}}=62
$$

where

$\mathrm{Z}=\mathrm{Z}$-score at $95 \%$ confidence interval $=1.96$

$\mathrm{P}=$ prevalence rate $(20 \%)$

$\mathrm{q}=$ Failure rate $(80 \%)$

$\mathrm{d}=$ error rate $(10 \%)$

Sixty-two participants were required in each facility of study.

\section{The study population}

Briefly, participants included consenting pregnant women who had come to attend their antenatal clinic but who were feeling unwell. Pregnant women that had other symptoms than self-reported fever were excluded. These participants attending antenatal clinics (ANC) were interviewed by researchers trained, to administer the semi-structured questionnaire. Socio-demographic characteristics, obstetrics and gynecology history, history of illness - especially febrile episodes, medication they were using during current pregnancy and their health-behavioral pattern such as possession and utilization of LLIN and use of Intermittent Preventive Treatment of malaria in pregnancy (IPT). $0.5 \mathrm{ml}$ venous blood sample was collected into labeled EDTA microtainer bottles. Malaria microscopy was performed as earlier described ${ }^{24}$ and hematocrit was determined by measuring Packed Cell Volume (PCV) in microhematocrit tubes spun in hematocrit centrifuge at $12,000-15,000 \mathrm{rpm}(\mathrm{xG})$ for 5 minutes and read using a hematocrit reader (Hawksley, England). Thick and thin blood films were made according to WHO specification ${ }^{14}$ and the thin smears fixed with methanol. The slides were allowed to air dry until the next day when they were stained for 30 minutes using 3\% Giemsa stain. The slides were examined under 100X oil immersion lenses and parasite density per $\mu \mathrm{l}$ was calculated by multiplying the number of parasites per high power field (HPF) by 500 , based on the assumptions that $5-8 \mu 1$ of blood is used in making a thick blood films and that $0.002 \mu \mathrm{l}$ of blood is in a HPF. ${ }^{25}$ To declare a slide negative, at least 200 high powered fields were read. Anemia was classified as mild (PCV $<36 \%$ ), moderate (PCV $23.3-33.2 \%$ ) or severe (PCV < $23.3 \%){ }^{26}$

\section{Inclusion/exclusion criteria}

Women who lived in the communities where the health facilities were located and who were consulting only for ante-natal care at these facilities were included in the study. Those who were brought in as emergency obstetric cases or women consulting for casual gynecological cases were excluded from the study. Also excluded were non-indigenes and those on admission for chronic systemic illnesses.

\section{Data analysis}

Data were analyzed using Stata-13. The mean, median, mode and various rates were determined for continuous variables such as age, and PCV. Geometric mean parasite densities were calculated, and Students t-test and chi squared analysis were used to compare differences. Differences of means were considered significant at a $95 \%$ confidence limit i.e. when $\mathrm{P}$ values are below 0.05 . Association was determined by computing logistic regression analysis of positive participants with other exposure variables at $95 \%$ confidence interval

\section{Consent and ethical approval}

The purpose of the study was explained to the pregnant women and the researcher requested for their consent to include them as participants in the study. The study was conducted as a sub-study of another study "Characterization of molecular markers associated with Plasmodium falciparum resistance to antimalarial drugs and evaluation of PCR methods for parasite density estimation in rural and semi-urban site in southwest Nigeria" for which ethical approval was obtained from the Nigerian Institute of Medical Research Institutional Review Board. All work was performed according to the guidelines for human experimentation in clinical research and Helsinki declaration

\section{Results}

\section{Malaria in pregnancy}

Table $1 \&$ Figure 1 of the 113 pregnant women enrolled in the study, only $22(19.5 \%)$ were positive for malaria parasites with a geometric mean parasite density of 7,500 and a mean PCV of $26.8 \pm 6.6 \%$. In all, 
$19(16.8 \%)$ of the study subjects were in the first trimester of whom $3(15.8 \%)$ were parasite-positive with a GMPD of 339.7, $54(47.8 \%)$ were in the second trimester among whom $8(14.8 \%)$ were positive for malaria parasites with a GMPD of 1077.4 and $40(35.4 \%)$ were in their third trimester among whom $11(27.5 \%)$ had malaria parasitemia with a GMPD of 715.3. Malaria parasites were observed more among women in their first pregnancy $(8 / 32,25.0 \%$; GMPD $=390.3)$ than among those in the second $(4 / 32,12.5 \%, \mathrm{GMPD}=5040.4)$ or more than two $(10 / 49,20.4 \%$, GMPD $=590.3)$ pregnancies. Figure 1 illustrates the status of malaria parasitemia among the study subjects showing that malaria was most prevalent among pregnant women aged 26-30 years and least among those aged 20 years or less. Women in the third trimester of pregnancy were more than twice likely to be positive for malaria parasite $(\mathrm{OR}=2.14,95 \% \mathrm{CI}: 0.83,5.50)$ than those in other trimesters. Those in their first pregnancy were 1.60 times as likely to be positive for malaria parasites than secundigravida or multipara women. Overall, malaria parasitemia was observed more in the $3^{\text {rd }}$ trimester $(11,27.5 \%)$ and among those pregnant for the first time $(8,25.0 \%)$

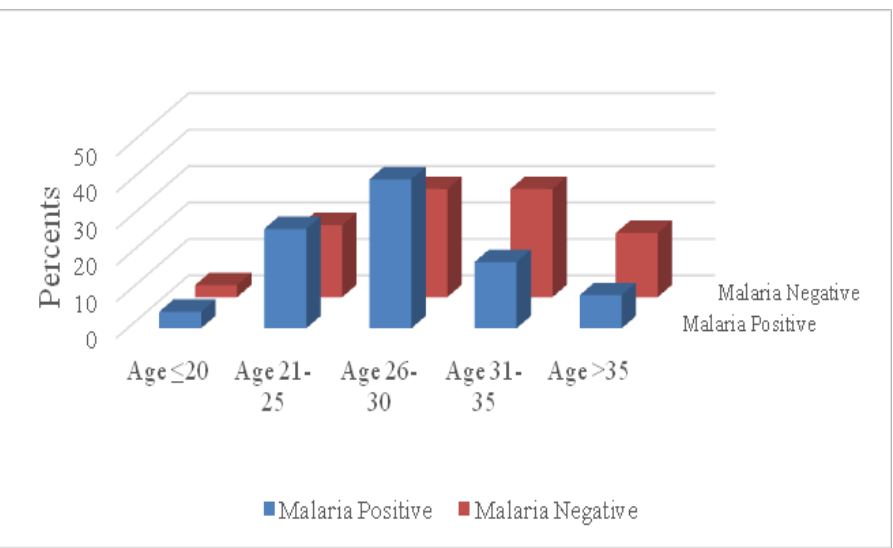

Figure I Proportion of pregnant women who were positive or negative for malaria parasites by age group in the study.

Table I Frequency distribution of parasitized and non-parasitized pregnant women with anemia and in various trimester and gravidity with malaria parasitemia

\begin{tabular}{|c|c|c|c|c|c|c|c|c|c|c|c|c|c|c|c|c|c|c|c|c|c|c|c|}
\hline \multirow{3}{*}{ Variable } & \multirow{3}{*}{ Item } & \multicolumn{8}{|l|}{ Anemia } & \multicolumn{2}{|l|}{ PCV } & \multicolumn{6}{|c|}{ Trimester } & \multicolumn{6}{|c|}{ Gravidity } \\
\hline & & \multicolumn{2}{|l|}{ None } & \multicolumn{2}{|l|}{ Mild } & \multicolumn{2}{|c|}{ Moderate } & \multicolumn{2}{|l|}{ Severe } & \multirow[b]{2}{*}{ Mean } & \multirow[b]{2}{*}{ $\pm s d$} & \multicolumn{2}{|l|}{$\left.\right|^{\text {st }}$} & \multicolumn{2}{|l|}{$2^{\text {nd }}$} & \multicolumn{2}{|l|}{$3^{\text {rd }}$} & \multicolumn{2}{|l|}{ I } & \multicolumn{2}{|l|}{2} & \multicolumn{2}{|l|}{$>2$} \\
\hline & & Freq & $\%$ & Freq & $\%$ & Freq & $\%$ & Freq & $\%$ & & & Freq & $\%$ & Freq & $\%$ & Freq & $\%$ & Freq & $\%$ & Freq & $\%$ & Freq & $\%$ \\
\hline \multirow{2}{*}{$\begin{array}{l}\text { Malaria } \\
\text { parasites }\end{array}$} & Pos. & 3 & 14.3 & 0 & 0.0 & 12 & 18.5 & 7 & 46.7 & 26.8 & 6.6 & 3 & 15.8 & 8 & 14.8 & 11 & 27.5 & 8 & 25.0 & 4 & 12.5 & 10 & 20.4 \\
\hline & Neg. & 18 & 85.7 & 12 & 100.0 & 53 & 81.5 & 8 & 53.3 & 30.8 & 6.0 & 16 & 84.2 & 46 & 85.2 & 29 & 72.5 & 24 & 75.0 & 28 & 87.5 & 39 & 79.6 \\
\hline$\chi^{2}$ & & \multicolumn{2}{|l|}{0.44} & \multicolumn{2}{|l|}{2.00} & \multicolumn{2}{|l|}{0.75} & \multicolumn{2}{|l|}{8.16} & \multicolumn{2}{|l|}{$\mathrm{t}=0.62$} & \multicolumn{2}{|l|}{0.02} & \multicolumn{2}{|l|}{1.43} & \multicolumn{2}{|l|}{2.55} & \multicolumn{2}{|l|}{0.87} & \multicolumn{2}{|l|}{0.8} & \multicolumn{2}{|l|}{0.05} \\
\hline P-value & & \multicolumn{2}{|l|}{0.51} & 0.16 & & 0.75 & & 0.004 & & 0.27 & & 0.90 & & 0.23 & & 0.11 & & 0.35 & & 0.36 & & 0.82 & \\
\hline OR & & 0.64 & & undefined & & 0.86 & & 4.84 & & - & & 0.74 & & 0.56 & & 2.14 & & 1.60 & & 0.50 & & 1.11 & \\
\hline $95 \% \mathrm{CI}$ & & $0.17,2.40$ & & undefined & & $0.34,2.2$ & & $1.53,15.35$ & & - & & $0.19,2.8$ & & $0.21,1.46$ & & $0.83,5.50$ & & $0.59,4.28$ & & $0.15,1.61$ & & $0.44,2.8$ & \\
\hline $\begin{array}{l}\text { Geometri } \\
\text { Parasite D }\end{array}$ & $\begin{array}{l}\text { Mean } \\
\text { ensity }\end{array}$ & 1,900 & & 0 & & 497.4 & & 1018.3 & & 7500 & & 339.7 & & 1077.4 & & 715.3 & & 390.3 & & 5040.4 & & 590.3 & \\
\hline $\begin{array}{l}95 \% \text { Conf } \\
\text { Interval }\end{array}$ & lence & $\begin{array}{l}2.21 \\
1,632,452 .\end{array}$ & & 0 & & $57.68,4$ & 290.03 & $\begin{array}{l}68.27 \\
15187.12\end{array}$ & & & & $0.16,718$ & 191.5 & $\begin{array}{l}50.64 \\
22927.55\end{array}$ & & $\begin{array}{l}\text { 104.23, } \\
4909.28\end{array}$ & & $\begin{array}{l}56.98, \\
2673.82\end{array}$ & & $\begin{array}{l}20.41, \\
\text { I2444222 }\end{array}$ & & $\begin{array}{l}5055, \\
6893.95\end{array}$ & \\
\hline PCV & Mean & 39.1 & & 34.4 & & 28.6 & & 20.3 & & - & & 30.9 & & 29.5 & & 30.4 & & 29.6 & & 30.4 & & 30.1 & \\
\hline
\end{tabular}

Table 2 Frequency distribution of anemia categories in various trimesters and gravidity of study subjects

\begin{tabular}{|c|c|c|c|c|c|c|c|c|c|c|}
\hline \multirow[t]{3}{*}{ Variable } & \multirow[t]{3}{*}{ Sub-variable } & \multirow[t]{3}{*}{ Statistics } & \multicolumn{8}{|l|}{ Anemia } \\
\hline & & & \multicolumn{2}{|l|}{ None } & \multicolumn{2}{|l|}{ Mild } & \multicolumn{2}{|c|}{ Moderate } & \multicolumn{2}{|l|}{ Severe } \\
\hline & & & Freq. & $\%$ & Freq. & $\%$ & Freq. & $\%$ & Freq. & $\%$ \\
\hline & & Total & 5 & 23.8 & 0 & 0.0 & 12 & 18.5 & 2 & 13.3 \\
\hline & & $\chi^{2}$ & 0.90 & & 1.53 & & 0.30 & & 0.0003 & \\
\hline & First & P-value & 0.34 & & 0.21 & & 0.59 & & 0.99 & \\
\hline & & $95 \% \mathrm{Cl}$ & $0.55,5.52$ & & undefined & & $0.48,3.67$ & & $0.15,3.55$ & \\
\hline & & Total & 6 & 28.6 & 9 & 75.0 & 32 & 49.2 & 7 & 46.7 \\
\hline & & $\chi^{2}$ & 3.82 & & 2.86 & & 0.13 & & 0.01 & \\
\hline \multirow[t]{5}{*}{ Trimester } & Second & P-value & 0.05 & & 0.09 & & 0.72 & & 0.93 & \\
\hline & & $\chi^{2}$ & 2.89 & & 0.23 & & 0.64 & & 0.18 & \\
\hline & Third & P-value & 0.09 & & 0.63 & & 0.42 & & 0.69 & \\
\hline & & OR & 0.44 & & 0.58 & & 0.73 & & 1.25 & \\
\hline & & $95 \% \mathrm{Cl}$ & $0.17,0.15$ & & $0.15,2.26$ & & $0.33,1.59$ & & $0.4 I, 3.82$ & \\
\hline
\end{tabular}


Malaria and anemia among pregnant women living in communities along the coast of Lagos Lagoon,

\begin{tabular}{|c|c|c|c|c|c|c|c|c|c|c|}
\hline & & Total & 8 & 38.1 & 3 & 25.0 & 15 & 23.1 & 6 & 40.0 \\
\hline & & $\chi^{2}$ & 1.21 & & 0.00 & & 2.07 & & 1.16 & \\
\hline & \multirow[t]{5}{*}{ Primigravida } & P-value & 0.27 & & 1.00 & & 0.15 & & 0.28 & \\
\hline & & OR & 1.74 & & 0.83 & & 0.55 & & 1.85 & \\
\hline & & $(95 \% \mathrm{Cl})$ & $(0.64,4.72)$ & & $(0.21,3.28)$ & & $(0.24,1.25)$ & & $(0.60,5.69)$ & \\
\hline & & Total & 5 & 23.8 & 3 & 25.0 & 21 & 32.3 & 3 & 20.0 \\
\hline & & $\chi^{2}$ & 0.26 & & 0.00 & & 1.20 & & 0.21 & \\
\hline \multirow[t]{8}{*}{ Gravidity } & Secundigravida & P-value & 0.61 & & 1.00 & & 0.27 & & 0.64 & \\
\hline & & OR & 0.75 & & 0.83 & & 1.60 & & 0.59 & \\
\hline & & $95 \% \mathrm{Cl}$ & $0.25,2.26$ & & $0.21,3.28$ & & $0.69,3.76$ & & $0.16,2.27$ & \\
\hline & & Total & 8 & 38.1 & 6 & 50.0 & 29 & 44.6 & 6 & 40.0 \\
\hline & & $\chi^{2}$ & 0.29 & & 0.24 & & 0.10 & & 0.08 & \\
\hline & Multigravida & P-value & 0.59 & & 0.62 & & 0.75 & & 0.78 & \\
\hline & & OR & 0.77 & & 1.35 & & 1.13 & & 0.85 & \\
\hline & & $95 \% \mathrm{Cl}$ & $0.30,2.02$ & & $0.4 I, 4.47$ & & $0.53,2.40$ & & $0.28,2.58$ & \\
\hline
\end{tabular}

Table 3 Frequency distribution of anemia, malaria infestation, trimester and gravidity according to age group

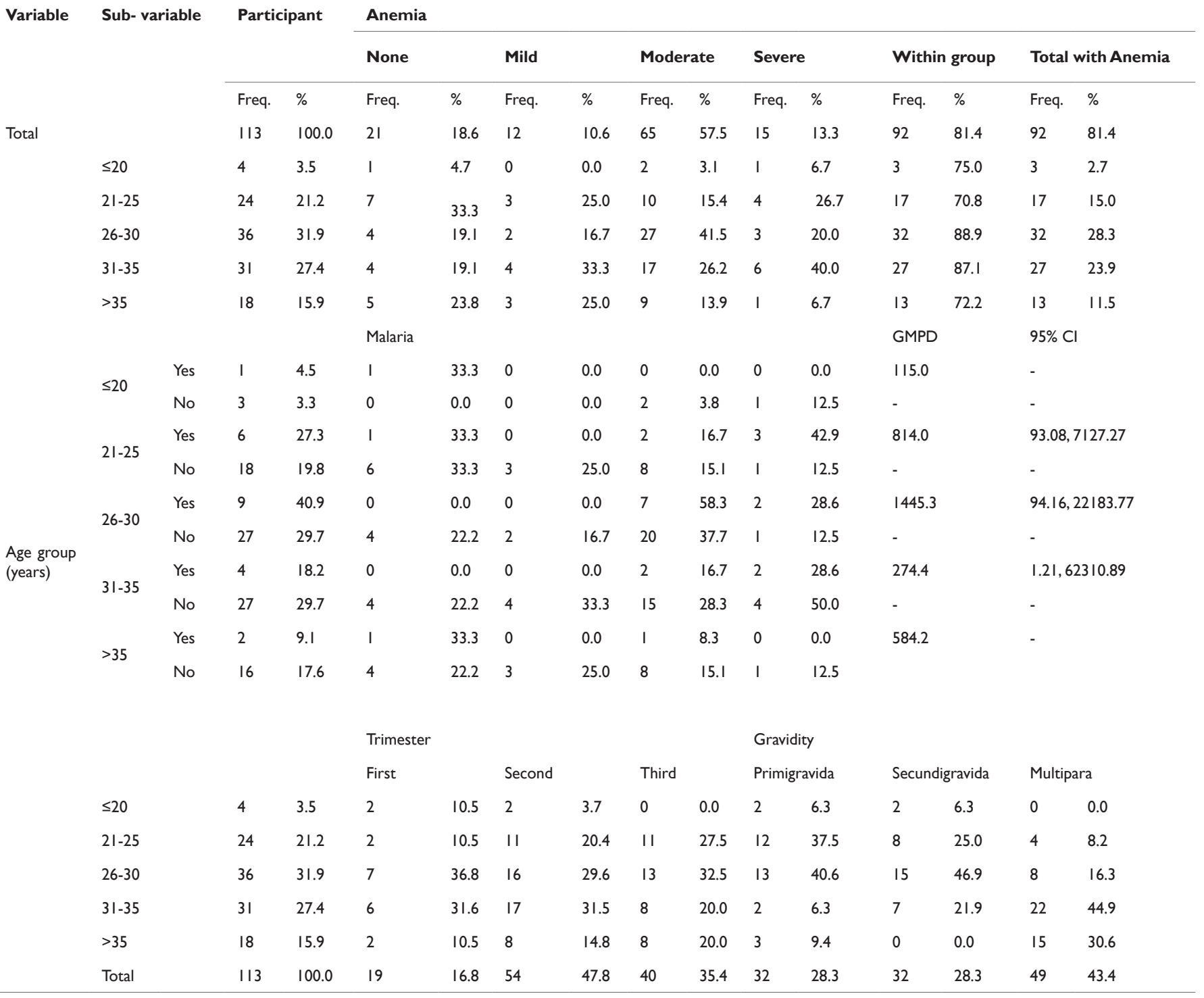

\section{Anemia in pregnancy}

Table 1 shows that $21(18.6 \%), 12(10.6 \%), 65(57.5 \%)$ and 15
$(13.3 \%)$ pregnant women had no, mild, moderate and severe anemia respectively. The mean PCV of malaria-positive pregnant women in the study was lower $(26.8 \pm 6.6)$ than that of parasite-negative women

Citation: Olukosi A,Afolabi BM. Malaria and anemia among pregnant women living in communities along the coast of Lagos Lagoon, South-west Nigeria. Int J Pregn \& Chi Birth. 2018;4(6):I75-I82. DOI: 10.15406/ipcb.2018.04.00I22 
(30.8 \pm 6.0$)$ though the difference was not statistically significant. Table 2 indicates that, of the $21(18.6 \%)$ women with no anemia, $5(23.8 \%)$, $6(28.6 \%)$ and $10(47.6 \%)$ were in their $1^{\text {st }}, 2^{\text {nd }}$, and $3^{\text {rd }}$ trimester while 8 $(38.1 \%), 5(23.8 \%)$ and $8(38.1 \%)$ were primigravida, secundigravida and multipara respectively. Of the $12(10.6 \%)$ women with mild anemia, none was in the first trimester, $9(75.0 \%)$ and $3(25.0 \%)$ were in the $2^{\text {nd }}$ and $3^{\text {rd }}$ trimester respectively. Among the $65(57.5 \%)$ with moderate anemia, most $(32,49.2 \%)$ were in the second trimester while the least $(12,18.5 \%)$ were in their first trimester. Majority ( 7 , $46.7 \%$ ) of those with severe anemia were in the $2^{\text {nd }}$ trimester. Women in the first trimester were 1.74 time more likely to present with no anemia $\left(\chi^{2}=0.90, \mathrm{P}\right.$-value $\left.=0.34, \mathrm{OR}=1.74,95 \% \mathrm{CI}=0.55,5.52\right)$ and were also 1.33 times more likely to develop moderate anemia $\left(\chi^{2}=0.30, \mathrm{P}\right.$-value $\left.=0.59, \mathrm{OR}=1.33,95 \% \mathrm{CI}=0.48,3.67\right)$ than women in other trimesters. Those in second trimester were 3.73 times more likely to present with mild anemia $\left(\chi^{2}=2.86, \mathrm{P}\right.$-value $=0.09, \mathrm{OR}=3.73$, $95 \% \mathrm{CI}=0.95,14.61)$, while women in the third trimester were 1.25 as likely to develop severe anemia as those in first or second trimester $\left(\chi^{2}=0.18, \mathrm{P}\right.$-value $\left.=0.69, \mathrm{OR}=1.25,95 \% \mathrm{CI}=0.41,3.82\right)$. Primigravida were 1.74 times more likely to have no anemia $\left(\chi^{2}=1.21, \mathrm{P}\right.$-value $=0.27$, $\mathrm{OR}=1.74,95 \% \mathrm{CI}=0.64,4.72)$ but were also 1.85 times to develop severe anemia $\left(\chi^{2}=1.16, \mathrm{P}\right.$-value $\left.=0.28, \mathrm{OR}=1.85,95 \% \mathrm{CI}=0.60,5.69\right)$ compared to others. Secundigravida were 1.60 times more likely to develop moderate anemia $\left(\chi^{2}=1.20, \mathrm{P}\right.$-value $=0.27, \mathrm{OR}=1.60,95 \%$ $\mathrm{CI}=0.69,3.76)$ and multipara were 1.35 times more likely to develop mild anemia $\left(\chi^{2}=024, \mathrm{P}\right.$-value $\left.=0.62, \mathrm{OR}=1.35,95 \% \mathrm{CI}=0.41,4.47\right)$. Figure 2 illustrates the absolute Packed Cell Volume (PCV) by age of each pregnant woman showing that the lowest PCV was observed in a pregnant woman aged 24 years. Mild, moderate and severe anemia occurred mostly in the $2^{\text {nd }}$ than in any trimester and mostly among multigravida women. Women in the first trimester of pregnancy were less likely to have malaria parasitemia $(\mathrm{OR}=0.74,95 \% \mathrm{CI}: 0.19,2.80)$ and as such were 1.74 times as likely to have no anemia $(\mathrm{OR}=1.74$, $95 \%$ CI: $0.55 ; 5.52)$. Though women in the second trimester were less likely to have malaria parasitemia $(\mathrm{OR}=0.56,95 \% \mathrm{CI}: 0.21,1.46)$, they were 3.73 times more likely to develop mild anemia than other women $(\mathrm{OR}=3.73,95 \% \mathrm{CI}: 0.95 ; 14.61)$. The highest proportion of pregnant women with anemia $(48 / 92,52.2 \%)$ occurred in the second trimester and amongst multi-gravidae.

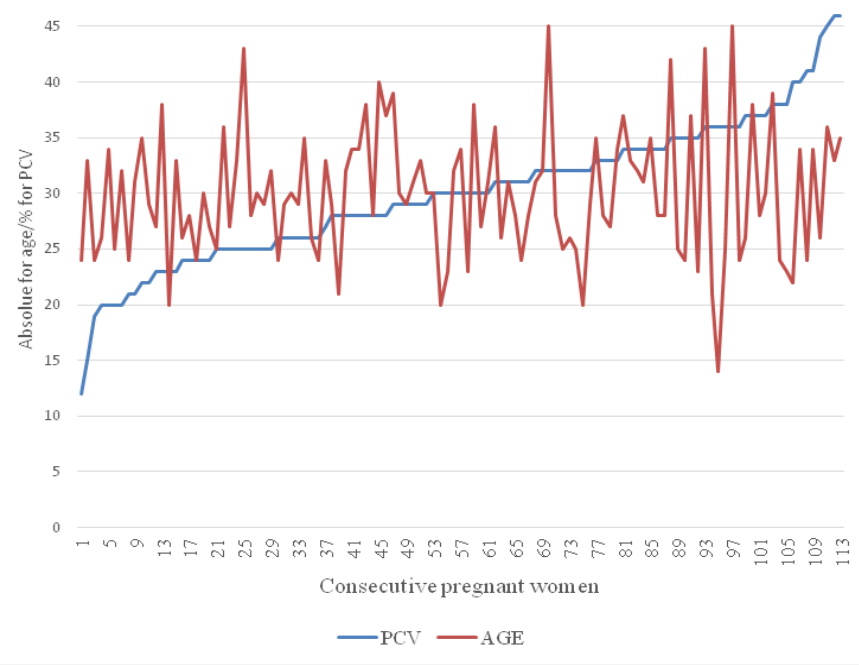

Figure 2 Distribution of Packed Cell Volume among all the study subjects by age.

\section{Malaria and anemia in pregnancy}

A total of $21(18.6 \%)$ women had no anemia, of whom $3(14.3 \%)$ were positive for malaria parasites with a geometric mean parasite density of 1,900 and mean ( \pm sd) PCV of 39.1 (3.5). Interestingly, none of the 12 women with mild anemia had malaria parasitemia with a mean
( \pm sd) PCV of $34.4(0.5)$. The mean ( \pm sd) PCV of the 65 women with moderate anemia was $28.6( \pm 2.8)$ and $12(18.5 \%)$ of them had malaria parasitemia with a GMPD of 497.4. A total of 15 women with severe malaria had a mean $( \pm \mathrm{sd})$ PCV of 20.3 (3.1) and GMPD of 1018.3. Pregnant women with no anemia were not likely to have malaria parasitemia $\left(\chi^{2}=0.44, \mathrm{P}\right.$-value $=0.51, \mathrm{OR}=0.64,95 \%$ CI: $\left.0.17,2.40\right)$. The odds of pregnant women with moderate anemia to have malaria parasitemia was stronger $\left(\chi^{2}=0.75, \mathrm{P}\right.$-value $=0.75, \mathrm{OR}=0.86,95 \% \mathrm{CI}$ : $0.34,2.20)$ than the odds among those without anemia. However, those with severe anemia were approximately five times more likely to have malaria parasitemia $\left(\chi^{2}=8.16, \mathrm{P}\right.$-value $=0.004, \mathrm{OR}=4.84,95 \%$ CI: $1.53,15.35)$ compared to all other pregnant women. Table 3 also shows the distribution of anemia, malaria parasitemia, trimester and gravidity by the age of study subjects, indicating in all $92(81.4 \%)$ had one level or the other of anemia, that anemia occurred mostly among those aged $26-30$ years $(32,28.3 \%)$, that $12(10.6 \%), 65(57.5 \%)$ and $15(13.3 \%)$ presented with mild, moderate or severe anemia and that only $21(18.6 \%)$ had no anemia. Among those with no anemia, 7 $(33.3 \%)$ were aged $21-25$ years while most $(6,40.0 \%)$ of those with severe anemia were aged 31-35 years. The Table also shows that most $(9,40.9 \%)$ of the 22 parasite-positive pregnant women were aged 26-30 years, majority $(7,58.3 \%)$ of whom were moderately anemic. Further, $19(16.8 \%), 54(47.8 \%)$ and $40(35.4 \%)$ of the women were in first, second or third trimester of pregnancy, while $32(28.3 \%)$, $32(28.3 \%)$ and $49(43.4 \%)$ were primigravida, secundigravida or multipara respectively. Though multiparous women were 1.11 likely to be positive for malaria parasites $(\mathrm{OR}=1.11,95 \% \mathrm{CI}$ : $0.44,2.83)$, they were not likely to present with severe anemia $(\mathrm{OR}=0.85,95 \%$ CI: $0.28,2.58$ ). Figure 3 explains that pregnant women may have some malaria parasitemia without developing anemia, may have some mild anemia without malaria parasitemia but that most cases of severe anemia in pregnancy are associated with a significant density of malaria parasitemia. Anemia was commonest (32/92, 28.3\%) in the age range 26-30 years Table 3 .

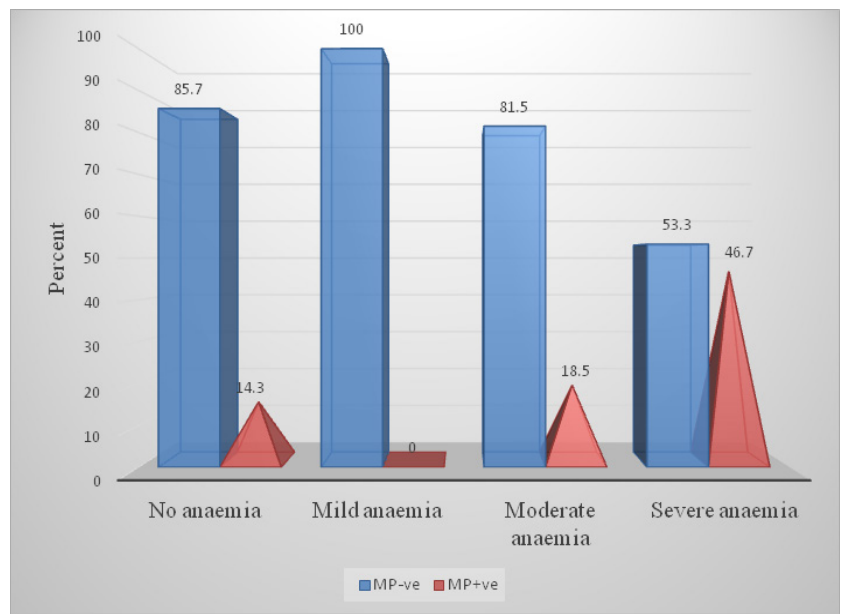

Figure 3 Distribution of various degrees of anemia among pregnant women with and without malaria parasitaemia.

\section{Malaria commodities, herbal medication and anemia in pregnancy}

The mean PCV of those $(\mathrm{n}=28)$ who possessed LLIN $(30.0 \pm 5.8)$ but did not use it was not significantly different from that of women $(\mathrm{n}=15)$ who slept under LLIN night before survey $(30.0 \pm 6.5)$ (Table 4). However, the mean PCV of pregnant women who slept under LLIN and still consumed herbal $(26.0 \pm 5.1)$ tea was significantly lower $(\mathrm{t}=-2.43$, P-value $=0.02)$ than that of pregnant women who slept under LLIN but did not consume herbal tea $(30.4 \pm 6.3)$. Regardless of whether the pregnant woman was parasitized or not, the mean PCV of those who consumed herbal tea $(28.2 \pm 5.2)$ was significantly lower $(\mathrm{t}=-2.24$, P-value $=0.01)$ than those who did not consume herbal tea $(30.8 \pm 6.5)$ in pregnancy Table 4. 
Table 4 Mean Packed Cell Volume, prevalence of anemia and malaria parasitemia relative to possession and use of various anti-malaria commodities

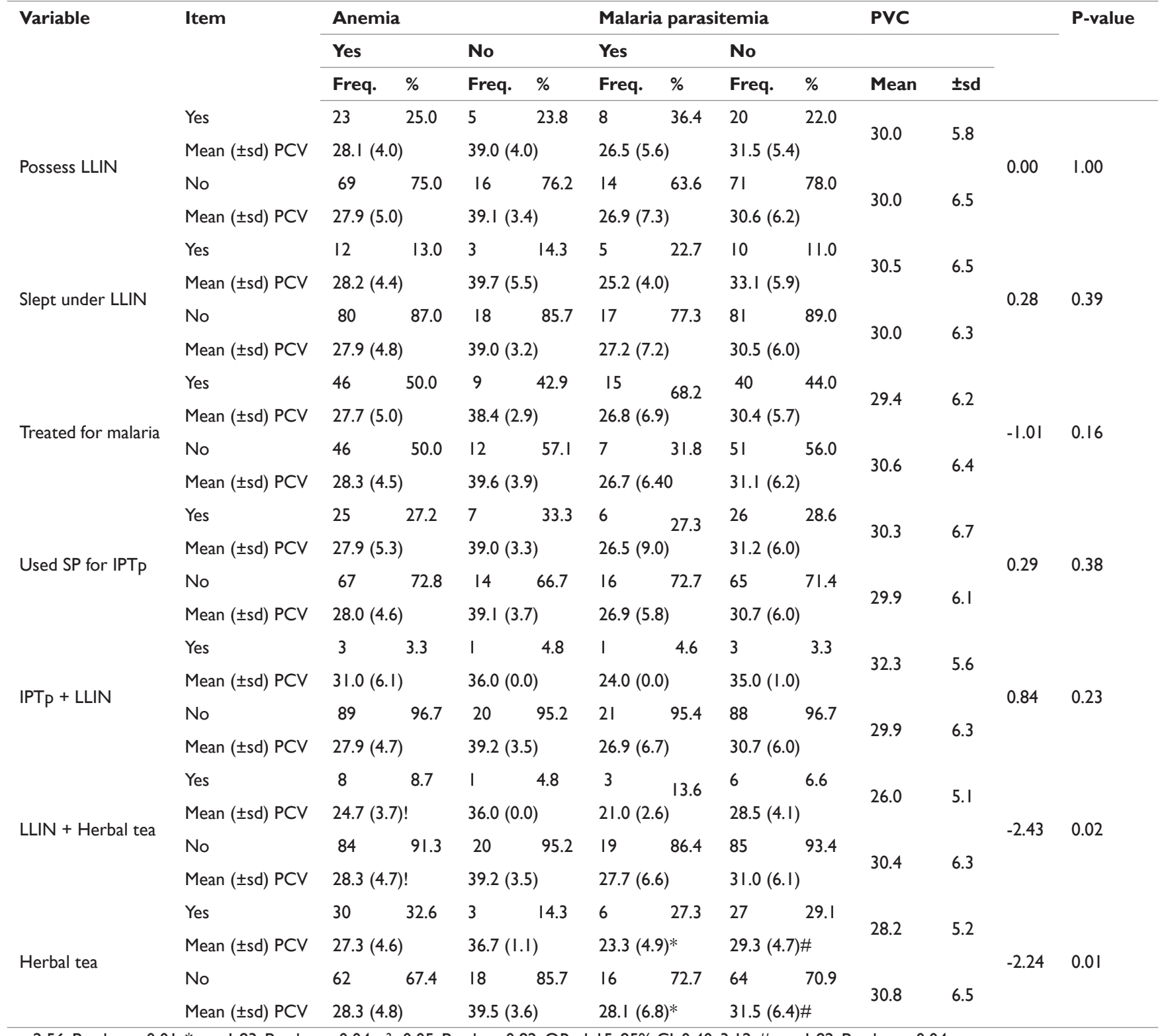

$! \mathrm{t}=-2.56, \mathrm{P}$-value $=0.0 \mathrm{I}, *_{\mathrm{t}}=-\mathrm{I} .83, \mathrm{P}$-value $=0.04, \chi^{2}=0.05, \mathrm{P}$-value=0.82, OR=I.I5, 95\% Cl: 0.40, 3.I2, \#t $=-\mathrm{I} .82, \mathrm{P}$-value $=0.04$

Table 5 Chi-square analysis of proportions with and without malaria parasitemia and anemia

\begin{tabular}{|c|c|c|c|c|c|c|c|}
\hline \multirow{2}{*}{\multicolumn{2}{|c|}{ Variable }} & \multicolumn{4}{|c|}{ Malaria parasitemia } & \multirow{2}{*}{\multicolumn{2}{|c|}{ Total }} \\
\hline & & \multicolumn{2}{|l|}{ Yes } & \multicolumn{2}{|l|}{ No } & & \\
\hline & & Freq. & $\%$ & Freq. & $\%$ & Freq. & $\%$ \\
\hline \multirow{2}{*}{ Anemia } & Yes & 19 & 86.4 & 73 & 80.2 & 92 & 81.4 \\
\hline & No & 3 & 13.6 & 18 & 19.8 & 21 & 18.6 \\
\hline \multicolumn{2}{|l|}{ Total } & 22 & 19.5 & 91 & 80.5 & 113 & 100.0 \\
\hline \multicolumn{2}{|l|}{$\chi^{2}$} & \multicolumn{6}{|l|}{$0.13^{*}$} \\
\hline \multicolumn{2}{|l|}{$\mathrm{P}$-value } & \multicolumn{6}{|l|}{0.72} \\
\hline \multicolumn{2}{|l|}{ OR } & \multicolumn{6}{|l|}{1.56} \\
\hline \multicolumn{2}{|c|}{$\begin{array}{l}95 \% \text { Confidence } \\
\text { Interval }\end{array}$} & \multicolumn{6}{|c|}{$0.42,5.86$} \\
\hline
\end{tabular}

\section{No malaria, No anemia}

Overall, $18(19.8 \%)$ of the pregnant women in the study had no malaria parasitemia and no anemia. The means $( \pm \mathrm{sd})$ and range of age and PCV of these group of women were 30.4 (7.2), 21-45 years and 39.2 (3.7), 36-46 respectively. Women with no malaria parasitemia pregnancy were 1.56 more likely to present with no anemia than others with malaria parasitemia $\left(\chi^{2}=0.13, \mathrm{P}\right.$-value $=0.72, \mathrm{OR}=1.56$, 95\% CI: 0.42, 5.86) Table 5.

\section{Discussion}

This study aimed to highlight the degree of malaria-induced and non-malaria-induced anemia in different age groups, different trimesters and in varying gravidity among pregnant women living in communities along the Lagoon coast in Lagos Nigeria. It should be appreciated with great concern that majority of the approximate 500,000 women who die annually in pregnancy occur most in the developing world ${ }^{27,28}$ that are mostly malaria-endemic. Malaria and anemia in any stage of pregnancy are almost always devastating to 
the fetus, the mother, the family and the community. Base on the guidelines of WHO, ${ }^{29}$ the Federal Ministry of Health ${ }^{30}$ have streamlined current strategies controlling malaria in pregnancy to include trio of Intermittent Preventive Therapy (IPTp) using SulphadoxinePyrimethamine (SP), vector control and prompt treatment of acute illness. There are some major key findings that this paper hopes to deliberate upon. The first is the alarming prevalence of anemia which was observed to be $81.4 \%$ among the study subjects. This was higher than the $70 \%$ prevalence reported. and $61 \%$ stated by Shipala et al. $^{27}$ in Kenya, than the national prevalence of $56 \%$ in pregnant women in Ghana, ${ }^{31-33}$ the $63 \%$ prevalence in India $^{34}$ and the $40.4 \%$ reported elsewhere in Nigeria. ${ }^{35}$ Malaria may not be the only cause of anemia in pregnancy. Anemia in pregnancy may also be as a result of other sinister events such as placenta previa near the internalos of the cervical canal, nutritional deficiency (Iron and Folate) and worm infestation, especially in the developing world. These other forms of anemia possibly compound malaria-induced anemia in pregnancy. For example, it is known that Iron deficiency and malaria cause anemia in pregnancy, which increase the risk of poor delivery and birth outcomes. A woman with sustained anemia in pregnancy runs the risk of maternal death, still birth, low birth weight, and fetal impairment. ${ }^{36}$ Malaria parasites are known not only to destroy the red blood cells, posing danger to the pregnant woman, but also to cause fibrosis of the placenta thus preventing adequate nutrients to be transported to the fetus, leading to fetal distress, intrauterine growth retardation (IUGR), low birth weight (LBW), abortion, stillbirth, fetal death or, in rare cases, congenital malaria or possibly congenital malformation.

The mother's immune system, in the presence of malaria, is such that the system must accept the fetus but still guard against infections. Regulatory T cells, a special type of T lymphocytes, play a crucial role in maintaining this fetal tolerance by migrating from the blood towards the placenta, where they secrete interleukin 10 (IL-10), an immunesuppressive mediator. ${ }^{37}$ According to Fievet et al. ${ }^{38}$ intra-uterine exposure to malarial antigens influence innate immune activation with impaired co-stimulatory abilities of dendritic cells, and to modify toll-like receptor-induced cytokine responses which may leave the neonate more susceptible to other infections, as in the case of HIV. ${ }^{39-41}$ Others have reported a reduction in cell-mediated immune responses to malaria parasite antigens during pregnancy. ${ }^{42-43}$ Another key finding in this study is the low prevalence of $19.5 \%$ in malaria parasitemia, comparable to a finding from Kenya ${ }^{31}$ but far below the $54.0 \%$ reported by Amadi \& Nwankwo ${ }^{40}$ in Southeast Nigeria. Unlike in other studies, peak prevalence of malaria parasitemia in pregnancy was observed in the third trimester $(11,27.5 \%)$ than in the first or second trimester. The prevalence of malaria parasitemia was highest in the age group of 26-30 years which also has the highest GMPD. This was contrary to what was reported from Gabon but may be due to more women having their first child in this age group. Another surprising finding is a 14-year-old pregnant girl (data not shown). Teenage pregnancy may be due to unreported rape, peer-pressure or myth that primary dysmenorrhea in girl can be alleviated by having sex. More studies on factors contributing to teenage pregnancy in Nigeria are required. Fourthly, the consumption of herbal teas commonly referred to as Agbo Iba (Herbal tea for fever) among pregnant women in Nigeria. The mean PCV of pregnant women who consumed Agbo Iba was lower than that of pregnant women who did not, regardless of whether they slept under LLIN or not. In fact, women who consumed Agbo Iba were 1.15 times more likely to be positive for malaria parasite compared with those who did not. A study reported that Agbo Iba has prophylactic properties against malaria parasite but more researches are needed in this area. Fifth, many of the pregnant women in this study did not use antimalaria commodities such as LLIN or SP for malaria prophylaxis, even though the State Government gave out these commodities free. This should be a cause for concern among malaria programmers and decision makers as using these commodities have been reported to drastically decrease malaria transmission. The State should initiate a study on why pregnant women do not sleep under LLIN or use Sulphadoxine-pyrimethamine for malaria prophylaxis.
Finally, $18(15.9 \%)$ pregnant women did not present with either malaria or anemia, a phenomenon that is not often reported. This is the ideal situation that every malaria program aspires to, which could be achieved through aggressive health education, focused ante-natal care, health promotion and family care of the pregnant woman.

\section{Conclusion and recommendations}

This study found a high prevalence of anemia among pregnant women living in communities surrounding the Lagoon of Lagos. The overall prevalence of malaria parasitemia among the study subject was $19.5 \%$ whereas the prevalence of anemia was $81.4 \%$ indicating that malaria may not be the only cause of anemia. However, malaria was more associated with severe anemia. While higher prevalence of malaria infection was associated with third trimester of pregnancy and with primigravida, higher prevalence of anemia was associated with second trimester of pregnancy and multigravida. The highest Geometric mean parasite density was observed among those aged 26-30 years, the age group with the highest prevalence of anemia. There was no significant difference in the mean Packed Cell Volume (PCV) of women who possessed LLIN but did not sleep under these commodities and those who did. However, the mean PCV of women who consumed herbal tea (Agbo Iba) in pregnancy was significantly lower than the mean PCV of those who did not. A very low proportion of pregnant women used Sulphadoxine-pyrimethamine for malaria prophylaxis in pregnancy and fewer slept under LLIN night before survey. A success story is the 18 women who did not present with anemia or malaria parasitemia in the study. A cohesive package of interventions is desirable to avert malaria, iron deficiency, and anemia during pregnancy. The Federal and State Ministries of Health should regularly update their policies and guidelines to reflect World Health Organization (WHO) recommendations for avoiding malaria and anemia in pregnancy. There is also urgent need to continually train and re-train health providers on application of WHO guidelines. Government at all levels should also find out, through survey, and address the reason(s) why women do not use malaria commodities in pregnancy. Subsequent studies may be directed at determining immune responses and role of white blood cells, especially, Neutrophils to determine their specific role in placenta malaria. Studies are also needed on folic acid, folates and other minerals that play a role in improving the anemia status of pregnant women, especially in subSaharan Africa.

\section{Acknowledgments}

None.

\section{Conflicts of interest}

The author declares there are no conflicts of interest.

\section{References}

1. World Health Organization. UNICEF. The Africa Malaria Report; 2003.

2. Ouma P, van Eijk AM, Hamel MJ, et al. Malaria and anaemia among pregnant women at first antenatal clinic visit in Kisumu, western Kenya. Trop Med Int Health. 2007;12(12):1515-1523.

3. Brabin BJ. An analysis of malaria in pregnancy in Africa. Bull World Health Organ. 1983;61(6):1005-1016.

4. Menendez C. Malaria during pregnancy: a priority area of malaria research and control. Parasitology Today. 1995;11(5):178-183.

5. Steketee RW, Nahlen BL, Parise ME, et al. The burden of malaria in pregnancy in malaria-endemic areas. Am J Trop Med Hyg. 2001;64(1-2 Supp):28-35. 
6. Hviid L, Salanti A.VAR2CSA and protective immunity against pregnancy-associated Plasmodium falciparum malaria. Parasitology. 2007;134(Pt13):1871-6.

7. Fried M, Duffy PE. Adherence of Plasmodium falciparum to chondroitin sulfate A in the human placenta. Science. 1996;272 (5267):1502-1504.

8. Center for Disease Control and Prevention. Treatment of Malaria: Guidelines for Clinicians (United States).

9. Pereira MA, Clausen TM, Pehrson C, et al. Placental sequestration of Plasmodium falciparum malaria parasites is mediated by the interaction between VAR2CSA and chondroitin sulfate A on Syndecan-1. PLoS Pathog. 2016;12(8):e1005831.

10. Schantz-Dunn J, Nour NM. Malaria and Pregnancy: A Global Health Perspective. Rev Obstet Gynecol. 2009;2(3):186-192.

11. Miaffo C, Some F, Kouyate B, et al. Malaria and anemia prevention in pregnant women of rural Burkina Faso. BMC Pregnancy and childbirth. 2004;4:18.

12. Sharma L, Shukla G. Placental Malaria: A New Insight into the Pathophysiology. Front Med (Lausanne). 2017;4:117.

13. Koram KA, Kwadwo AK, Owusu-Agyei S, et al. Seasonal Profiles of Malaria Infection, Anaemia, and Bednet Use among Age Groups and Communities in Northern Ghana. TM \& IH. 2003;8(9):793-802.

14. Okebe J, Mwesigwa J, Agbla SC, et al. Seasonal Variation in Haematological and Biochemical Reference Values for Healthy Young Children in The Gambia. BMC Pediatr. 2016;16(1):5.

15. World Health Organization. Malaria in pregnancy. 2017.

16. Athuman M, Kabanywanyi AM, Rohwer AC. Intermittent Preventive Antimalarial Treatment for Children with Anaemia. Cochrane Database Syst Rev. 2007;13(1):1-55.

17. World Health Organization. Haemoglobin Concentrations for the Diagnosis of Anaemia and Assessment of Severity. Geneva, Switzerland; 2011

18. Jaleel R, Khan A. Severe anaemia and adverse pregnancy outcome. Journal of Surgery Pakistan International. 2008;13(4):143-150.

19. Olukosi A, Afolabi BM. Self-reported acute febrile illness, malaria and anemia among pregnant women in communities surrounding the Lagoon of Lagos, South-west Nigeria. J Preg Neonatal Med. 2018;2(1):15-26.

20. World Health Organization. Basic laboratory methods in medical parasitology. Geneva, Switzerland; 1991:114-170.

21. Molineaux L, Gramiccia G. The Garki Project. Research on the epidemiology and control of malaria in Sudan savanna of West Africa. Geneva, Switzerland; 1980.

22. World Health Organization. Haemoglobin concentrations for the diagnosis of anemia and assessment of severity. Vitam Miner. Nutr Inf Syst. Geneva; 2011. p. 1-6.

23. AbouZahr C. Global burden of maternal death and disability. Br Med Bull. 2003;67:1-11.

24. WHO. Maternal mortality ratio (per 100000 live births). 2010.

25. World Health Organization. A Strategic Framework for Malaria Prevention and Control During Pregnancy in the African Region. AFR/MAL/04/01. Brazzaville: WHO Regional Office for Africa; 2004.

26. Federal Ministry of Health. National Antimalarial Treatment Guideline. Abuja: FMOH; 2005

27. Shipala EK, Sowayi GA, Kagwiria MP, et al. Prevalence Of Anemia
Among Teenage Pregnant Girls Attending Antenatal Clinic In Two Health Facilities In Bungoma District, Western Kenya. Journal of Biology, Agriculture and Healthcare. 2013;3(6):67-75.

28. Intiful FD, Wiredu EK, Asare GA, Asante M, Adjei DN. Anemia in pregnant adolescent girls with malaria and practicing pica. Pan African Medical Journal. 2016;24:96.

29. Muhil M, Sembian U. Anaemia and adverse birth outcome of teenage pregnancy in rural area of Tamilnadu. Indian Journal of Maternal and Child Health. 2011;13(2):6.

30. Dim CC, Onah HE. The prevalence of anemia among pregnant women at booking in Enugu, South Eastern Nigeria. Medscape General Medicine. 2007;9(3):11.

31. Uneke CJ, Duhlinska DD, Igbinedion EB. Prevalence and public-health significance of HIV infection and anemia among pregnant women attending antenatal clinics in south-eastern Nigeria. J Health Popul Nutr. 2007;25(3):328-335.

32. Dobaño C, Requena P. ISGlobal, Changes in the Immune Response during Pregnancy are associated with Protection against Malaria Infection and Better Delivery Outcomes. Malaria in Pregnancy Consortium (MiPC) ISGlobal

33. Fievet N, Varani S, Ibitokou S, et al. Plasmodium falciparum exposure in utero, maternal age and parity influence the innate activation of foetal antigen presenting cells. Malar J. 2009;8:251.

34. Gbédandé K, Varani S, Ibitokou S, et al. Malaria modifies neonatal and early-life toll-like receptor cytokine responses. Infect Immun. 2013;81(8):2686-2696.

35. Adegnika AA, Köhler C, Agnandji ST, et al. Pregnancy-associated malaria affects toll-like receptor ligand-induced cytokine responses in cord blood. J Infect Dis. 2008;198:928-936.

36. Steiner K, Myrie L, Malhotra I,et al. Fetal immune activation to malaria antigens enhances susceptibility to in vitro HIV infection in cord blood mononuclear cells. J Infect Dis. 2010;202:899-907.

37. Ricke CH, Staalsoe T, Koram K, et al. Plasma antibodies from malariaexposed pregnant women recognize variant surface antigens on Plasmodium falciparum-infected erythrocytes in a parity-dependent manner and block parasite adhesion to chondroitin sulphate. A J Immunol. 2000;165(6):3309-3316

38. Fievet N, Cot M, Ringwald P, et al. Immune response to Plasmodium falciparum antigens in Cameroonian primigravidae: evolution after delivery and during second pregnancy. Clin Exp Immunol. 1997;107:462467.

39. Rasheed FN, Bulmer JN, Dunn DT, et al. Suppressed peripheral and placental blood lymphoproliferative responses in first pregnancies: relevance to malaria. Am J Trop Med Hyg. 1993;48:154-160.

40. Amadi ANC, Nwankwo PC. Malaria Parasitemia and anemia among pregnant women in Umuahia Metropolis. J Appl Sci Environ Manage. 2012;16(4):367-370.

41. Tay SCK, Agboli E, Abruquah HH, et al. Malaria and anemia in pregnant and non-pregnant women of child-bearing age at the University Hospital, Kumasi, Ghana. Open Journal of Medical Microbiology. 2013;3:193-200.

42. Bouyou-Akotet MK, Ionete-Collard DE, Mabika-Manfoumbi M, et al. Prevalence of Plasmodium Falciparum Infection in Pregnant Women in Gabon. Malar J. 2003;2(1):18.

43. Nwabuisi C. Prophylactic effect of multi-herbal extract 'Agbo-Iba' on malaria induced in mice.East Afr Med J. 2002;79(7):343-346. 